\title{
Reseña del libro: "International Arbitration in Latin America Energy and Natural Resources Disputes", editado por Gloria M. Álvarez, Mélanie Riofrio Piché, Felipe V. Sperandio con Celia Cañete
}

Javier Jaramillo Troya* Felipe Castro Zurita ${ }^{* *}$

Recibido/Received: 21/11/2021 Aceptado/Accepted: 22/11/2021

Reservas de hidrocarburos, concentración de petróleo, producción de gas natural, grandes proyectos hidroeléctricos. Sin duda alguna América Latina juega un rol preponderante en la economía global por su riqueza en cuanto a recursos naturales. Esta importancia cobra mayor relevancia si consideramos la apertura de los países latinoamericanos al comercio internacional y a las inversiones. Sin embargo, debido al largo plazo y a la volatilidad inherente a las modalidades contractuales, y sumando la inestabilidad política de la región, es común que surjan disputas sobre los contratos que regulan estos proyectos.

"International Arbitration in Latin America Energy and Natural Resources Disputes" es una obra única, pues se enfoca en el estudio del arbitraje internacional con un orientación especializada hacia el área de recursos naturales. Los editores, en su mayoría abogados latinoamericanos con estudios de posgrado en Europa, combinan sus conocimientos en civil law y common law para, en conjunto

* Asociado Senior en Pérez Bustamante \& Ponce. Secretario Arbitral CAM-CCQ, AMCHAM CAM y CIAM. Profesor de Arbitraje, Derecho de Daños y Litigación Oral en la Universidad San Francisco de Quito. Abogado por la Universidad San Francisco de Quito. Máster en Derecho por la Escuela de Derecho de la Universidad de Harvard.

** Estudiante de pregrado del Colegio de Jurisprudencia de la Universidad San Francisco de Quito. Correo electrónico: fjcastroz@outlook.com|fjcastro@estud.usfq.edu.ec 
con treinta y nueve contribuyentes de todo el mundo, ofrecer un análisis práctico y legal específico para cada uno de los sectores de importancia en los recursos naturales. Dadas las complejidades técnicas y jurídicas que emanan de su naturaleza, las controversias que surgen de estos sectores demandan un método adecuado de solución de conflictos que ofrezca la especialización necesaria para resolverlas. El libro presenta al arbitraje como el método más adecuado y capaz de satisfacer las necesidades y demandas de los inversionistas y equilibrarlas con la facultad regulatoria de los Estados.

La obra editada por Gloria Álvarez, Mélanie Riofrio Piché y Felipe Sperandio hace un análisis completo sobre los principales conflictos en materia de arbitraje y recursos naturales y energía. Comenzando por las bases del arbitraje en estas materias, pasando por los marcos regulatorios estatales, y finalizando con el estudio de los fenómenos sociales y políticas ambientales que tienen lugar cuando existen proyectos de inversión en el área de los recursos naturales, la obra es un análisis exhaustivo sobre el tema. Su propósito: explicar cómo el arbitraje se ha consolidado como el método preferido para resolver disputas complejas referentes a energía y recursos naturales en las que se involucran partes domésticas e internacionales.

La primera parte expone cómo la continua institucionalización del arbitraje internacional en América Latina da cuenta de la intención de los Estados de atraer inversión extranjera y promover sus relaciones comerciales. Además, explora las complejidades procesales y contractuales que implican los proyectos relacionados a la energía y recursos naturales. Entre ellas destacan los largos y profundos procesos que deben enfrentar los inversionistas debido a la multiplicidad de partes, contratos, y acuerdos arbitrales. La obra presenta un análisis profundo, pues no solo expone los problemas asociados a los proyectos en el área de energía y recursos naturales sino que repasa también las soluciones utilizadas por los contratantes como, por ejemplo, la estipulación de cláusulas paraguas, acuerdos de arbitraje compatibles con el tipo de disputas en concordancia con los sistemas legales de cada país de América Latina, entre otros.

Otro de los enfoques principales que trae la obra es el rol de los Estados y sus instrumentalidades cuando se ejecutan contratos 
de concesión o similares y su involucramiento como partes en el arbitraje. Que existan intereses tanto públicos como privados da paso a conflictos sobre arbitrabilidad, políticas públicas o incluso derechos constitucionales como el debido proceso, lo que puede influir en la ejecución y reconocimiento del laudo a posteriori. Además, da cuenta de los principales conflictos sustantivos dentro de los marcos regulatorios de cada Estado. La imprevisibilidad de transacciones tan complejas implica la necesidad de una adecuada regulación sobre los riesgos asociados y la interpretación de los contratos que, como se expone en esta sección, debe realizarse teniendo en cuenta la transacción o inversión en su totalidad.

Una característica única de la obra es que expone los conflictos específicos que se dan en el área de recursos naturales con un enfoque particular por sector. Así, su segunda parte realiza un estudio sobre las particularidades en las disputas de contratos petroleros, gas natural, minería, electricidad, y energía renovable. El análisis destaca las diferencias en los sistemas normativos de cada Estado del que dependen las modalidades contractuales aplicables a cada transacción. Por ejemplo, en la mayoría de países de la región, los contratos referentes a minería e hidrocarburos necesariamente acarrean la participación del Estado como parte, debido a que son catalogados como bienes estatales. En el caso de Ecuador, bajo este marco se pueden aplicar diversas modalidades contractuales como concesiones, contratos de participación, contratos de gestión delegada, entre otros. La obra expone la existencia de diferentes marcos regulatorios para cada sector con diferencias en cuanto a su flexibilidad y amplitud, a los que los inversores deben adaptarse para ejecutar sus proyectos.

En la tercera parte del libro se observan cuestiones y fenómenos que han surgido con motivo de los procesos arbitrales en controversias en América Latina. Los contribuyentes realizan un repaso sobre la corrupción en el arbitraje de inversiones y cómo el sistema ha unido esfuerzos para paliar este fenómeno. Esta sección se refiere, también, a las particularidades en el reconocimiento y ejecución de laudos internacionales. Aunque parezca que América Latina es un grupo de Estados muy similares por los lazos lingüísticos y culturales que los unen, la obra demuestra las diferencias de los distintos países en cuanto al arbitraje en 
materia de recursos naturales. Por ejemplo, Estados como México, Colombia y Brasil se han abierto a las inversiones a través del Convenio CIADI y su deferencia hacia los tribunales extranjeros. Es otro el caso de Venezuela, Bolivia o Ecuador, que han denunciado el Convenio CIADI en los últimos años. Aunque Ecuador revirtió esta situación ratificando nuevamente la Convención en el último mes, Perú, por otro lado, amenaza con denunciarlo bajo el nuevo régimen de gobierno. Finalmente, la obra se enfoca en un área que, cada vez más y con mayor fuerza, cobra relevancia en el desarrollo de un proceso arbitral: el cálculo de daños. El libro analiza las distintas complejidades legales, técnicas y económicas que conlleva el cálculo de daños con un enfoque en diferentes métodos, plazos, tasas aplicables, entre otros. No obstante, sintetiza cuales son los métodos más utilizados en los procesos sobre energía y recursos naturales, lo que fortalece el corazón de la obra.

La cuarta parte del libro se enfoca en Brasil como Estado y su experiencia en arbitrajes relacionados con energía y recursos naturales. Brasil es, mundialmente, uno de los jugadores más importantes en proyectos que implican explotación de recursos naturales. Por ello, su legislación, experiencia y casuística resultan valiosos para el desarrollo del resto de la región. La obra abre la puerta para que otros jugadores latinoamericanos revisen la experiencia brasileña en relación con las disputas arbitrales en materia de recursos naturales de cara a su desarrollo regulatorio y jurisprudencial.

El uso y explotación de recursos también da lugar a conflictos políticos y sociales, que son analizados en la quinta parte del libro. El caso de Venezuela resulta ilustrativo y por ello se le dedica un capítulo. Es extraordinario el número de arbitrajes de inversión en los que Venezuela ha sido parte y que han tenido origen en sus agitados vientos políticos. Esta experiencia ofrece jurisprudencia importante sobre temas como la denuncia al Convenio CIADI o la problemática que tiene lugar cuando dos sujetos distintos claman ser el representante del Estado. En cuanto a lo social, la obra ofrece una visión que incluye una perspectiva de derechos humanos y su compatibilidad con las cláusulas de estabilidad que, si bien son de utilidad para atraer inversiones, pueden restringir la facultad regulatoria de los Estados e incidir sobre las políticas públicas. De 
todas formas, la obra explora los puntos de compatibilidad entre la estabilidad ofrecida a un inversor y la facultad regulatoria de los Estados. La obra también realiza un interesante estudio sobre el ejercicio de los derechos de terceros interesados como es el caso de las comunidades indígenas de los países de la región que, normalmente, habitan las zonas donde se explotan determinados recursos naturales.

Un tema que no podía prescindirse al hablar de energía y recursos naturales es el impacto ambiental, expuesto en la sexta parte del libro. Se ofrece un análisis sobre el cambio climático y la transición energética en el marco del arbitraje. Esta sección ilustra cuáles son los conflictos que pueden surgir al respecto y la forma en la que han sido resueltos en sede arbitral. Además, expone la necesidad de implementar las normas internacionales sobre cambio climático, o, a su vez, la importancia de que cada Estado promulgue normativa ambiental que deberá ser discutida en controversias en las que confluyan disputas sobre recursos naturales y alegaciones de afectaciones al ambiente.

El libro dedica su última parte a un sistema que, en cuanto a disputas relacionadas con recursos naturales, impacto ambiental y fenómenos comunitarios es cada vez más relevante: la mediación. El libro expone experiencias en las que la mediación ha resultado ser un método exitoso para resolver conflictos inversor-Estado en sectores energéticos, haciendo énfasis en el valor agregado que trae la mediación cuando están en la balanza intereses económicos y de protección a la naturaleza. De todas formas, el capítulo admite que su práctica se encuentra todavía en desarrollo y la importancia de promover su crecimiento.

En conclusión, a través de la revisión de casos relevantes referentes a energía y recursos naturales, el libro analiza cómo se han desarrollado los conflictos en cada sector específico y en cada Estado de América Latina. El libro recopila de manera eficaz la información más importante sobre los marcos regulatorios, las estrategias para la ejecución de contratos y el buen devenir de los complejos procesos que surgen de la práctica en estos sectores en Latinoamérica. Además, realiza un repaso sobre los problemas sociales, políticos, económicos y ambientales que tienen lugar en el área de energía y recursos naturales. La variedad de temas que 
abarca de forma eficiente y especializada hacen que sea una obra fundamental para practicantes y árbitros en las áreas que trata. La experiencia de los editores y contribuyentes brinda un aporte único para lograr que el futuro de las inversiones y las relaciones comerciales sean de provecho para la economía latinoamericana y global a través de una fortalecida práctica arbitral. 